\title{
The geography of Chinese science
}

Andersson, David Emanuel; Gunessee, Saileshsingh; Matthiessen, Christian Wichmann; Find, Soren

Published in:

Environment and Planning A

DOI:

10.1068/a130283p

Publication date:

2014

Document version

Early version, also known as pre-print

Citation for published version (APA):

Andersson, D. E., Gunessee, S., Matthiessen, C. W., \& Find, S. (2014). The geography of Chinese science. Environment and Planning A, 46(12), 2950-2971. https://doi.org/10.1068/a130283p 


\section{The geography of Chinese science}

Matthiessen, Christian Wichmann; Andresson, David Emanuel; Gunessee, Saileshsingh; Find, Søren

Published in:

Environment and Planning $\mathrm{A}$

Publication date:

2015

Document Version

Preprint (usually an early version)

Citation for published version (APA):

Matthiessen, C. W., Andresson, D. E., Gunessee, S., \& Find, S. (2015). The geography of Chinese science. Environment and Planning A, 46, 2950-2971. 


\title{
The geography of Chinese science
}

\section{David Emanuel Andersson, Saileshsingh Gunessee}

Nottingham University Business School China, 199 Taikang East Road, Ningbo 315100, Zhejiang, China; e-mail: david.andersson@nottingham.edu.cn, saileshsingh.gunessee@nottingham.edu.cn

\section{Christian Wichmann Matthiessen}

Department of Geosciences and Resource Management, University of Copenhagen, Øster Voldgade 10, København K 3460, Denmark; e-mail: cwm@geogr.ku.dk

\section{Søren Find}

Technical University of Denmark, Anker Engelunds Vej 1, Kgs. Lyngby 2800, Denmark; e-mail: sf@vitis.dtu.dk

Received 29 October 2013; in revised form 2 July 2014

\begin{abstract}
Chinese scientific output has increased dramatically in recent years, but its internal spatial structure has received scant attention. Estimated gravity models of intercity scientific coauthorships show that there are two types of spatial political bias in China, apart from the expected mass and distance effects. Intercity coauthorships involving Beijing are more common than Beijing's output volume and location would imply, and this Beijing bias is increasing over time. The second type of spatial political bias is greater intraprovincial collaboration than is accounted for by size and distance. The geography of Chinese science is thus not only monocentric as regards overall scientific output, but also exhibits unusually hierarchical collaboration patterns. Unlike in Europe and North America, national and regional capitals are becoming ever more important as scientific coordination centers.
\end{abstract}

Keywords: scientific collaboration, network, China, spatial political bias

\section{Introduction}

The recent rise of Chinese science has attracted considerable attention (Nature, 2013; Royal Society, 2011; Zhou and Leydesdorff, 2006). While China's annual economic growth amounted to about $10 \%$ in the first decade of the 21 st century, its scientific growth averaged 18\% per year between 1996 and 2008 (Royal Society, 2011, page 20). China's scientific growth is thus even more dramatic than its economic growth.

While this rise has resulted in a number of scholarly articles (Liefner and Hennemann, 2011; Zhou and Leydesdorff, 2006; Zhou et al, 2009), we still know little about the internal spatial structure of Chinese science. In particular, previous studies do not address the role that geography has played in scientific interaction among cities in China. ${ }^{(1)}$ Most such studies are descriptive and take a national or, at best, a provincial perspective. ${ }^{(2)}$

(1) It is scientists within cities that collaborate and not cities per se, but cities function as nodes that host scientists. In the intercity network literature this is referred to as a two-mode network with links between two different entities (scientists and cities) which is transformed into a one-mode network involving only one mode such as cities (see Liu et al, 2013).

${ }^{(2)}$ This relates to two aspects: the geographical scope (eg, continent or nation) and the spatial unit (eg, country or city region). Most studies focus on other scope-unit combinations than a nation and its city regions. Some studies overlap with this study by focusing either on cities or on a single nation. For example, Matthiessen et al $(2002 ; 2010)$ provide a global network analysis of cities whereas 
The aim of this paper is to understand the spatial structure of Chinese science, using an econometric application of the well-known gravity model of interacting nodes. It is widely known that Beijing has greater science output than can be accounted for by the size of its population or economy, even when compared with Chinese cities of otherwise similar size and sophistication such as Shanghai or Shenzhen. What is less well known is whether size and distance are the only important factors that explain the interactivity of Chinese science, which is what one would expect in market-driven spatial structures, or whether political prioritization of national and/or regional capitals introduces a spatial political bias. Statistical testing of potential spatial bias is our primary objective. A second question, which is conditional on the existence of spatial political bias, is whether this bias has changed over time. Studies of European interaction show that national border effects have been decreasing in recent years.

A supplementary question is to compare the efficacy of different measures of mass. The most common measure is the number of publications, which is easily observed but may be affected by endogeneity problems. Therefore we also include exogenous approximations of market or political input volumes such as city GDP and the number of national research universities in a city.

The paper proceeds as follows. The next section summarizes the recent growth of Chinese science, while section 3 introduces the application of gravity models and other approaches to scientific collaboration. Section 4 presents methods and a descriptive overview of the dataset, while section 5 presents the econometric results. The penultimate section is an exploratory extension that attempts to 'read between the lines' of the econometric estimates. Section 7 concludes.

\section{The rise of Chinese science}

Table 1 shows the world's top-twelve science city regions in three distinct periods. While Europe and North America dominate global rankings of science cities, these rankings are not entirely static. The two most conspicuous changes after 2000 have been the rise of three East Asian cities-Beijing, Shanghai, and Seoul-and the decline of Moscow. In 1996-98 there were no Chinese cities among the top-twelve city regions, while by 2010 Beijing and Shanghai had joined this group, with Beijing ranked first.

Table 2 lists thirty-one leading Chinese science cities in 2008-10 and their growth rates from 1996-98 to 2008-10. Beijing and Shanghai are not the only Chinese centers. Among the world's seventy-five largest science cities in 2008-10, nine were in Mainland China. These nine Chinese cities exhibited the nine highest SCI growth rates among the seventy-five cities between 1996 and 2010.

All thirty-one Chinese cities had high growth rates, not only the top nine. If we compare their growth with the top sixty-six cities outside China, only two cities (Lanzhou and Changchun) had lower growth rates than the fastest growing non-Chinese city, which was Seoul. Even so, these two lagging Chinese cities expanded faster than São Paolo, which ranked second among non-Chinese cities. The stylized facts thus suggest that there is an ongoing process whereby new science cities are continually emerging.

(2) (continued)

Havemann et al (2006) use trend analysis to study collaboration among German immunological institutes. The closest analogy to this study is Ponds et al (2007), which analyzes collaboration between Dutch NUTS3 regions. Frenken et al (2009) provide a literature survey and observe that "studies on collaboration patterns among regions or cities are rare" (page 224). 
Table 1. The world's top-twelve science city regions.

\begin{tabular}{|c|c|c|c|c|c|c|}
\hline \multirow[t]{2}{*}{ Rank } & \multicolumn{2}{|l|}{ 1996-98 } & \multicolumn{2}{|l|}{$2002-04$} & \multicolumn{2}{|l|}{$2008-10$} \\
\hline & city region & $\begin{array}{l}\text { SCI } \\
\text { papers }\end{array}$ & city region & $\begin{array}{l}\text { SCI } \\
\text { papers }\end{array}$ & city region & $\begin{array}{l}\mathrm{SCI} \\
\text { papers }\end{array}$ \\
\hline 1 & London & 69303 & Tokyo-Yokohama & 81798 & Beijing & 100835 \\
\hline 2 & Tokyo-Yokohama & 67628 & London & 73403 & London & 96856 \\
\hline 3 & $\begin{array}{l}\text { San Francisco Bay } \\
\text { Area }\end{array}$ & 50212 & $\begin{array}{l}\text { San Francisco Bay } \\
\text { Area }\end{array}$ & 56916 & Tokyo-Yokohama & 94043 \\
\hline 4 & Paris & 49438 & Osaka-Kobe & 54300 & Paris & 77007 \\
\hline 5 & Osaka-Kobe & 48272 & Paris & 53005 & $\begin{array}{l}\text { San Francisco Bay } \\
\text { Area }\end{array}$ & 75669 \\
\hline 6 & Moscow & 45579 & New York & 51047 & New York & 70323 \\
\hline 7 & Boston & 42454 & Boston & 49265 & Boston & 69250 \\
\hline 8 & New York & 41566 & Los Angeles & 44401 & Seoul & 67292 \\
\hline 9 & $\begin{array}{l}\text { Randstad } \\
\text { (Amsterdam) }\end{array}$ & 37654 & $\begin{array}{l}\text { Randstad } \\
\text { (Amsterdam) }\end{array}$ & 44094 & $\begin{array}{l}\text { Randstad } \\
\text { (Amsterdam) }\end{array}$ & 65527 \\
\hline 10 & Los Angeles & 37437 & Beijing & 42007 & Osaka-Kobe & 60615 \\
\hline 11 & Philadelphia & 29376 & Moscow & 41001 & Los Angeles & 58176 \\
\hline 12 & Berlin & 24514 & Seoul & 33083 & Shanghai & 50597 \\
\hline
\end{tabular}

Note: Calculated by the authors on the basis of data from Thomson Reuters' Science Citation Index (SCI). Chinese cities are shown in bold.

Table 2. The thirty-one (Chinese cities with more than 1500 papers in 2008-10) leading science cities in China (global top- 75 cities in bold).

\begin{tabular}{llcll}
\hline Rank & City (province) & $\begin{array}{l}\text { SCI } \\
\text { publications } \\
(2008-10)\end{array}$ & City (province) & $\begin{array}{l}\text { SCI growth (\%) } \\
(1996-98 \text { to } \\
2008-10)\end{array}$ \\
\hline & & & & 46.3 \\
1 & Beijing (Beijing) & $\mathbf{1 0 0 8 3 5}$ & Shenzhen (Guangdong) & 31.7 \\
2 & Shanghai (Shanghai) & $\mathbf{5 0 5 9 7}$ & Ningbo (Zhejiang) & 27.9 \\
3 & Nanjing (Jiangsu) & $\mathbf{2 7 6 4 7}$ & Qingdao (Shandong) & 26.6 \\
4 & Wuhan (Hubei) & $\mathbf{2 1 7 5 2}$ & Nanchang (Jiangxi) & 26.1 \\
5 & Guangzhou (Guangdong) & $\mathbf{2 0 9 8 7}$ & Chongqing (Chongqing) & 25.2 \\
6 & Hangzhou (Zhejiang) & $\mathbf{1 9 5 9 7}$ & Harbin (Heilongjiang) & 24.4 \\
7 & Xi'an (Shaanxi) & $\mathbf{1 7 5 4 5}$ & Nanning (Guangxi) & 23.4 \\
8 & Chengdu (Sichuan) & $\mathbf{1 4 7 1 6}$ & Zhengzhou (Henan) & 23.0 \\
9 & Tianjin (Tianjin) & $\mathbf{1 2 9 5 0}$ & Suzhou (Jiangsu) & $\mathbf{2 2 . 8}$ \\
10 & Changchun (Jilin) & 11824 & Guangzhou (Guangdong) & 21.9 \\
11 & Changsha (Hunan) & 11345 & Shijiazhuang (Hebei) & 21.4 \\
12 & Hefei (Anhui) & 11289 & Dalian (Liaoning) & $\mathbf{2 1 . 3}$ \\
13 & Harbin (Heilongjiang) & 11217 & Hangzhou (Zhejiang) & 21.1 \\
14 & Jinan (Shandong) & 10710 & Changsha (Hunan) & 20.8 \\
15 & Shenyang (Liaoning) & 9904 & Guiyang (Guizhou) & $\mathbf{2 0 . 7}$ \\
16 & Dalian (Liaoning) & 9658 & Xi'an (Shaanxi) & 20.5 \\
17 & Lanzhou (Gansu) & 8585 & Fuzhou (Fujian) & $\mathbf{2 0 . 2}$ \\
18 & Chongqing (Chongqing) & 7865 & Chengdu (Sichuan) & $\mathbf{2 0 . 0}$ \\
19 & Qingdao (Shandong) & 6693 & Wuhan (Hubei) & 19.9 \\
20 & Kunming (Yunnan) & 4948 & Taiyuan (Shanxi) & 19.9 \\
21 & Fuzhou (Fujian) & 4356 & Jinan (Shandong) & 19.8 \\
22 & Xiamen (Fujian) & 4295 & Kunming (Yunnan) &
\end{tabular}


Table 2 (continued).

\begin{tabular}{llcll}
\hline Rank & City (province) & $\begin{array}{l}\text { SCI } \\
\text { publications } \\
(2008-10)\end{array}$ & City (province) & $\begin{array}{l}\text { SCI growth (\%) } \\
(1996-98 \text { to }\end{array}$ \\
& & 4122 & Shanghai (Shanghai) & 18.1 \\
23 & Zhengzhou (Henan) & 3825 & Xiamen (Fujian) & 16.3 \\
24 & Suzhou (Jiangsu) & 3416 & Shenyang (Liaoning) & 16.3 \\
25 & Taiyuan (Shanxi) & 3229 & Nanjing (Jiangsu) & $\mathbf{1 6 . 2}$ \\
26 & Nanchang (Jiangxi) & 3082 & Tianjin (Tianjin) & $\mathbf{1 6 . 2}$ \\
27 & Shenzhen (Guangdong) & 2645 & Beijing (Beijing) & $\mathbf{1 6 . 0}$ \\
28 & Shijiazhuang (Hebei) & 1886 & Hefei (Anhui) & 14.7 \\
29 & Nanning (Guangxi) & 1768 & Lanzhou (Gansu) & 13.8 \\
30 & Ningbo (Zhejiang) & 1542 & Changchun (Jilin) & 13.3 \\
31 & Guiyang (Guizhou) & $\mathbf{4 2 4 8 3 0}$ & China (31 cities) & $\mathbf{1 8 . 2}$ \\
& China (31 cities) & &
\end{tabular}

\section{Theoretical background}

When investigating scientific collaboration in space, the gravity model is appropriate as it is the key model for analyzing spatial interaction. It has enjoyed considerable success in various empirical applications and rests on sound theoretical microfoundations. In what follows we provide an overview of the gravity model of scientific knowledge flows, as well as a brief outline of the most popular alternative, which is the network approach.

\subsection{The gravity approach}

\subsubsection{Theory}

Building on earlier literature, ${ }^{(3)}$ Beckmann $(1993 ; 1994 ; 1999)$ provides a gravity model of scientific knowledge flows. His probabilistic microlevel theory assumes that two rational agents (scientists) supply inputs into joint scientific production. The production function exhibits positive marginal products, diminishing returns to substitution, and constant returns to scale. The agents maximize collaborative scientific production net of costs when choosing their labor effort; costs include the time-dependent and distance-dependent costs of achieving effective interaction. Through a series of substitutions and extensions, Beckmann obtains a gravity equation with scientific knowledge flows between two locations, $i$ and $j$ :

$$
C_{i j}=N_{i} N_{j} \exp \left(-d_{i j}\right),
$$

where $N$ is the number of researchers in locations $i$ and $j$, and $d_{i j}$ is the distance between the two locations.

Andersson and Persson (1993) and Andersson and Andersson (2006, pages 215-216) offer a deterministic alternative to Beckmann's model. The main assumption is that the value of scientific activities is dependent on ideas and techniques generated in cities other than the scientist's home region. This is represented by $P$-functions, which depend on the inflow of ideas coming from other nodes (cities) in the science network. Such ideas can come in the form of information $(I)$ or knowledge $(K)$. While information is easily transmitted by communication modes such as the Internet, knowledge flows more often require face-to-face contacts.

${ }^{(3)}$ Isard (1960) documents early gravity applications in the social sciences, which served as precursors of later models and applications. Wilson (1970) and Sen and Smith (1995) provide the foundation for modeling probabilistic spatial interaction behavior, such as Beckmann (1993; 1994; 1999). Such models have been applied to the study of traffic flows, interregional trade, and migration flows. 
Further assumptions include that the value $(P)$ and production $(Q)$ functions are differentiable and concave with respect to inputs. To determine the optimal flows of local and interactive inputs, we maximize net value, $G_{i}$ :

$$
G_{i}=P_{i}(\boldsymbol{I}, \boldsymbol{K}) Q\left(L_{i}, K_{i}, I_{i}\right)-\sum_{j \neq i} \tau_{j i} I_{j i}-\sum_{j \neq i} \omega_{j i} K_{j i}-\omega_{i} K_{i}-\tau_{i} I_{i}-w_{i} L_{i},
$$

where $\boldsymbol{I}=\left\{I_{11}, \ldots, I_{j i}, \ldots, I_{n n}\right\}$ is a vector of information flows from node (city) $j$ to node (city) $i ; \boldsymbol{K}=\left\{K_{11}, \ldots, K_{j i}, \ldots, K_{n n}\right\}$ is a vector of knowledge flows from $j$ to $i ; L_{i}$ is labor in city $i$; $P_{i}$ is quality as measured by publication or citation score of city $i$; $Q_{i}$ is science output in city $i$; $\tau$ is price of information, including unit transaction and communication cost; $\omega$ is price of knowledge, including unit transaction and communication cost; $w$ is price (wage) of labor.

Maximization yields the marginal interactivity conditions:

$$
\left.\begin{array}{c}
\frac{\partial P_{i}}{\partial I_{i j}} Q_{i}-\tau_{j i}=0, \quad j=1, \ldots, n, i=1, \ldots, n, i \neq j ; \\
\frac{\partial P_{i}}{\partial K_{i j}} Q_{i}-\omega_{j i}=0, \quad j=1, \ldots, n, i=1, \ldots, n, i \neq j .
\end{array}\right\}
$$

These marginal interactivity conditions exhibit economies of scale in long-distance interaction, implying that the larger a node's scientific agglomeration is, the more globalized it will be in terms of the size and spatial scope of its interaction pattern. Working with a simplified form for $\partial P / \partial K$, the interactions $K_{i j}$ follow a gravity function:

$$
K_{i j}=Q_{i}^{\lambda_{1}} Q_{j}^{\lambda_{2}} f\left(d_{i j}\right),
$$

where $Q$ is scientific output (mass) in locations $i$ and $j$, while $\lambda_{1}$ and $\lambda_{2}$ are parameters that may be estimated empirically; $f\left(d_{i j}\right)$ is a distance friction function that reflects the impact of distance on space-bridging costs.

The gravity model thus implies that scientific collaboration between two locations increases proportionally with the product of the mass variables but declines with distance. Although both models arrive at gravity formulations that conform to feasible empirical analyses, only Beckmann's model uses inputs as mass variables. Thus, Beckmann's model implies the use of input variables such as the number of scientists rather than scientists' output. As far as we know, all published gravity-type estimations of scientific interactivity use output volumes, and thus conform to the deterministic model (Andersson and Andersson, 2006; Andersson and Persson, 1993).

\subsubsection{Comparable studies}

The gravity approach suggests that one should account for geographic proximity, since distance is often the best explanation of interaction quantities involving cities. Proximity facilitates face-to-face communication, which in turn facilitates the transmission of tacit knowledge as well as serendipitous discoveries, both of which stimulate the production of creative outputs such as scientific publications (Andersson and Persson, 1993). Moreover, face-to-face interaction may increase interpersonal trust, making it easier for people to collaborate (Ponds et al, 2007).

Gravity models allow researchers to study how the effects of various factors change over time. Most studies that have examined distance effects in science have, however, adopted a static framework, such as analyzing collaboration at one point in time or using pooled observations from several years (Hansen, 2013). There are a few exceptions, but Hoekman et al (2010) is the only gravity-type analysis that explicitly addresses change. Other things being equal, we would expect a decreasing effect of distance over time, since space-bridging costs have been falling as a result of technological progress and investments in transport and communication infrastructures. 
There are only a handful of studies that analyze scientific collaboration with the help of gravity models (Acosta et al, 2011; Andersson and Persson, 1993; Hoekman et al, 2009; 2010; Ponds et al, 2007; Scherngell and $\mathrm{Hu}, 2011) .{ }^{(4)}$ The distance effect is uniformly negative but the estimated magnitudes depend on the chosen measurement technique. ${ }^{(5)}$ The distance effects in studies that resemble the present study range from -0.23 to -0.70 . Hoekman et al (2010) show that in Europe the distance effect increased from 2000 to 2007. They explain this increase as reflecting the emergence of collaboration involving scientists in peripheral European regions, which will tend to cause a greater measured distance effect than if collaboration had remained confined to regions closer to the European core. Given China's size, we expect distance to be as important as it is in Europe. Still, the relevant question is not whether distance matters but how much it matters; how does it compare with distance frictions elsewhere and how does it evolve over time?

\subsubsection{Spatial political bias}

It is well known that a substantial share of Chinese science funding is attributable to governmental decision makers. In spite of recent globalizing tendencies, Jonkers (2010) contends that Chinese science is still a top-down system with little bottom-up scientist-driven research. Moreover, leading universities are with few exceptions located in Beijing or in provincial capital cities. It is thus likely that scientific collaboration patterns reflect political resource allocation decisions. ${ }^{(6)}$ Jonkers (2010, page 36) claims that this political influence implies a preference for funding large-scale collaborative projects in fields that policy makers deem important. He also claims (2010, pages 148-149) that there is a network of Chinese scientists who jointly decide on the allocation of research funds.

One would thus expect political priorities to matter more than economic factors in sciencerelated location choices. One illustration is the priority given to national or provincial capitals as the preferred locations for national universities. The booming centers for foreign direct investment and exports - primarily Ningbo, Shenzhen, and Suzhou - account for tiny shares of China's scientific publications, in spite of their high growth rates and per capita incomes (see table 2).

A hypothesis that conforms to the notion of spatial political bias is that we should expect the funding of scientific activities - including collaborative research projects - to prioritize Beijing as well as provincial capitals. The implication is an expected over-representation of linkages involving Beijing and provincial capitals.

(4) Only six studies of Chinese scientific collaboration address collaboration between spatially delimited areas and only one (Scherngell and $\mathrm{Hu}, 2011$ ) uses a gravity estimation. Our gravity-type model differs from that of Scherngell and $\mathrm{Hu}$ in three important ways. First, we use the global Science Citation Index database rather than a domestic Chinese database. This makes it possible to compare Chinese output and interactivity with cities outside China. Second, our spatial unit of analysis is a functional urban region rather than a province. The only provinces that approximate functional urban regions are Beijing, Shanghai, and Tianjin. Third, they analyze scientific collaboration for one single point in time (ie, 2007), which precludes panel techniques and analysis of dynamics.

${ }^{(5)}$ Some studies use alternative methods when examining the influence of distance (Katz, 1994; Liang and Zhu, 2002). Overall, comparable studies support the hypothesis that geographical proximity matters.

${ }^{(6)}$ Our explanation is consistent with a more general explanation of a 'Confucian hierarchical education system' which is defined as being molded by the national government, with a national entrance examination that supports a hierarchical university system. Top universities in the national system have three advantages: the best students, the most research funding, and the most attractive terms and conditions for faculty. These advantages mutually reinforce the dominance of established top universities such as Peking University, Tsinghua University, and Fudan University in China. Seen from this perspective, the mainland Chinese system resembles the research and education systems of Japan, South Korea, and Taiwan (see Marginson, 2011). 


\subsubsection{Spatial political bias: same-province effect}

The distance effect is just one facet of what a gravity model can measure. Though the theoretical gravity models do not include political biases such as capital-city overrepresentation, it is common to extend the basic model to account for such effects. Empirical studies of international science networks provide estimates of how international border crossings reduce interactivity between cities (Hoekman et al, 2010; Okubo and Zitt, 2004). ${ }^{(7)}$ While linguistic or cultural barriers are less important in China than in Europe, political barriers between provinces cannot be ruled out in light of the practice of Chinese science policy, which includes a division of labor between different levels of the spatial political hierarchy, such as nation, province, and city.

Indeed, Scherngell and $\mathrm{Hu}$ (2011) contend that regional protectionism as a manifestation of spatial political bias is pervasive in both science and industry. Others have argued that provincial governments are inward oriented in their science policies, protecting local institutes and universities with the aim of maximizing intraprovincial benefits (Chen and Wang, 2003; Yoon, 2011). However, assertions of provincial protectionism in science have so far relied on anecdotal evidence rather than econometric estimates.

In their study of Europe, Hoekman et al (2010) estimated not only the effects of national barriers, but also found that such barriers became less important between 2000 and 2010. There is thus some empirical support for the idea that European science is becoming more integrated. The Chinese analogy to Europe's national border effects is the 'same-province effect', which refers to the hypothesis that provincial funding organizations prefer to keep their funds within the same province.

\subsection{Other theoretical approaches}

The most common nongravity approaches for analyzing interregional scientific collaboration are various adaptations of network theory. ${ }^{(8)}$ The network approach provides a different way of examining scientific coauthorships, with the aim of identifying subnetworks or clusters of cities with stronger-than-average interlinkages. ${ }^{(9)}$

An approach that focuses on 'the world network of science cities' has been the most influential alternative to the gravity model in generating empirical studies. This approach takes its cue from Taylor (2004) and his notion of 'world city networks'. Matthiessen et al (2002; 2010; 2011) uses Science Citation Index (SCI) data to classify cities as belonging to different hierarchical 'levels' and 'bands' on the basis of their volume and interactivity. These attempts make use of a direct analogy of Taylor's (2004) classification, where 'world city' status depends on the locations of headquarters and offices of multinational corporations.

While existing network approaches to science cities provide a summary of the relative importance of different cities, it remains the case that Taylor and his followers do not provide

${ }^{(7)}$ There is a literature that looks at how national political or linguistic biases favor national over international collaboration. For example, Okubo and Zitt (2004) show that French border regions cooperate little with regions on the other side of the border, with only the Paris region exhibiting strong international linkages in science.

${ }^{(8)}$ The 'scientific collaboration in space' literature is mostly data driven and lacks a clear theoretical framework. Most studies offer descriptive analyses of collaboration, using trend analysis, matrix-based approaches, or indices to measure various aspects of scientific collaboration, including geographical proximity as one such aspect (see Havemann et al, 2006; Katz, 1994; Liang and Zhu, 2002).

${ }^{(9)}$ Most network studies do not use the city region as the analyzed spatial unit due to limited data availability (Frenken et al, 2009; White, 2011). Studies of interregional networks tend to infer connectivity from metrics of network centralization and clustering (Oner et al, 2010). Most network studies lack theoretical microfoundations. Liefner and Hennemann (2011) is probably the best attempt to provide a theoretical framework to connect network theory to regional spatial phenomena. 
any microanalytic theoretical foundation, in contrast with the gravity model. ${ }^{(10)}$ There are thus strong theoretical reasons for giving priority to the gravity model as the preferred starting point for quantitative analyses of intercity links.

\section{Data and methods}

\subsection{Data}

Scientific coauthorships remain the main form of scientific collaborative output (Ponds et al, 2007). SCI-indexed coauthorships comprise all published articles in about 6650 journals in science and engineering. ${ }^{(11)}$ Coauthorship counts use the street address associated with the institutional affiliation of each author of an article.

The spatial delimitation of each city approximates labor-market areas, thus including both a central city and its outlying suburbs. Comparable studies combine neighboring cities if the center-to-center time distance is less than 45 minutes (Matthiessen et al, 2002). In the Chinese case the labor-market areas in practice correspond to the urban districts of each included city, since the administrative delimitations of Chinese cities encompass rural hinterlands. China's universities and research institutes tend to have central urban locations, although suburban 'university districts' are becoming more common. Even so, there are no Chinese college towns as remote as College Station (Texas), Ithaca (New York), or State College (Pennsylvania).

The thirty-one included cities account for almost all SCI-indexed publications from mainland China (see table 2). The covered time periods are 1996-98, 2002-04, and 2008-10. These three-year periods are consistent with the network analyses of world science cities by Matthiessen et al (2010), making international comparisons possible.

There was little Chinese scientific output and few coauthored papers in the first of the three periods. The period from 1996 to 1998 is thus an 'embryonic' period, followed by a period of middling scientific growth between 2002 and 2004. The final period-from 2008 to 2010 - represents full-fledged growth involving much larger output quantities. These contrasts should enable us to capture the various spatial changes occurring within the Chinese science system.

\subsection{Why use cities as the unit of analysis?}

This study is part of the 'scientific collaboration in space' literature (see Frenken et al, 2009). What makes our work distinct is its focus on scientific collaboration between cities. There are a few reasons for this. First, science production clusters in places such as large cities and university towns and is more spatially concentrated than most types of production (Liefner and Hennemann, 2011; Matthiessen et al, 2002). Second, decreasing communication costs have not caused the obsolescence of cities. Instead, cities have reinforced their importance as coordination centers of spatially dispersed activities (Sassen, 1991). Third, cities do not exist in isolation: they are nodes in interconnected networks (Taylor, 2004). Fourth, functional

${ }^{(10)}$ Some recent developments in the world city network literature offer exploratory theoretical grounding using actor-based random utility modelling (see Liu et al, 2013).

${ }^{(11)}$ We recognize that the SCI is just one way of measuring scientific collaboration and output. It is also possible to use citations or patents, although the latter involve a different literature and a different set of challenges (see $\mathrm{Hu}, 2010$ ). We believe that both citation and, especially, patent data are associated with serious problems as regards the identification of actual spatial locations of the relevant inputs. Nevertheless, we acknowledge that the use of the SCI comes with the biases inherent in this type of data. For instance, Hennemann et al (2011) point out that there can be differences when using domestic bibliographic databases as opposed to international ones. However, given that science policy makers attach increasing value to the international visibility of research, we believe that our focus on the rise of Chinese science as measured by SCI publication counts is justified (Jonkers, 2010, page 13). An additional advantage is that an international database allows for direct comparisons between cities and networks in different parts of the world. 
urban regions correspond to integrated labor markets, including markets for scientific labor. Fifth, cities are better suited for the questions at hand-such as spatial political bias. For example, a 'same-province effect' necessitates a separation between intraprovincial and interprovincial links.

\subsection{Gravity estimation}

Scientific interaction is bidirectional. Unlike in trade, there is no obvious source or destination region when two or more scientists coauthor a paper. Adaptations of the gravity model for the purpose of analyzing scientific cooperation should therefore include only one volume or mass variable, typically the product of the total publication volumes of two regions. Additionally, coauthorships consist of nonnegative integer values (count data), which render ordinary least squares estimation inappropriate (Hilbe, 2011). Estimation of gravity models of coauthorships such as equation (4) thus tend to be based on a Poisson process:

$$
\operatorname{Pr}\left(C_{i j}\right)=\frac{\exp \left(-\mu_{i j}\right) \mu_{i j}^{C_{i j}}}{C_{i j} !}, \quad \mu_{i j}=\exp \left(\beta_{1}+\beta_{2} \ln M_{i} M_{j}+\beta_{3} \ln D_{i j}\right),
$$

where scientific collaboration $\left(C_{i j}\right)$ between cities $i$ and $j$ follows a Poisson distribution with conditional mean $\mu$. The mass variable $\left(M_{i} M_{j}\right)$ and distance variable $\left(D_{i j}\right)$ are dependent on this conditional mean.

An alternative count model is the negative binomial model. The key difference concerns the conditional variance. The Poisson regression model assumes a Poisson distribution, where the conditional mean of the dependent variable equals the conditional variance. It is, however, common for the conditional variance to exceed the conditional mean, especially when the count variable has more zeroes than a Poisson-distributed data-generating process would yield. The resulting overdispersion can be accounted for in the negative binomial model via an extra parameter denoted as $\alpha$ (Hilbe, 2011). In the case of Chinese coauthorships an overdispersion test consistently rejected the null hypothesis that the conditional variance of the dependent variable equals its conditional mean. Thus, the gravity-type regressions employ the negative binomial regression model. ${ }^{(12)}$

Table 3 describes and lists the sources of the dependent and independent variables in the gravity-type models. Our main mass variable (PUBMASS) follows the empirical literature and is the product of the SCI publication counts of two cities. As robustness checks we also consider alternative proxies for the mass variable: city publication products two years before the start of the observed coauthorship period (PUBMASS2); the product of the cities' GDP (GDPMASS); the product of the cities' volumes of tertiary teachers (TEACHMASS); and the product of the number of national universities in each of the two cities (UNIMASS). GDPMASS is often included in trade models and proxies for overall agglomeration economies. TEACHMASS and UNIMASS are proxies for investments in scientific research.

The motivation behind these variables is threefold. First, the alternative measures address potential endogeneity problems associated with PUBMASS. We adopt lagged values to address potential simultaneity problems, while random effects and time dummies control for omitted variables that may be important. ${ }^{(13)}$ Second, TEACHMASS and UNIMASS are potential input variables in line with Beckmann's gravity model. Third, a comparison of the effects of UNIMASS and GDPMASS may offer clues regarding the relative importance of politics-driven and market-driven interaction processes. The former variable reflects investments in science, while the latter reflects overall agglomeration economies, including potential knowledge externalities from industry.

${ }^{(12)}$ See Scherngell and $\mathrm{Hu}$ (2011) for a formal presentation of the negative binomial model that is applied to scientific flows.

${ }^{(13)}$ Acosta et al (2011) is the only study to address the first of these issues apart from the present study. 
Table 3. Variable descriptions and data sources.

\begin{tabular}{|c|c|c|}
\hline Variable name & Description & Source \\
\hline \multicolumn{3}{|l|}{ Dependent variable } \\
\hline Coauthored papers & $\begin{array}{l}\text { Number of coauthored papers by city pair for } \\
\text { three three-year periods }\end{array}$ & $\begin{array}{l}\text { Thomson-Reuters SCI } \\
\text { database }\end{array}$ \\
\hline \multicolumn{3}{|c|}{ Independent variables } \\
\hline \multicolumn{3}{|c|}{ Mass variables } \\
\hline PUBMASS & $\begin{array}{l}\text { Log of (product of total number of SCI } \\
\text { publications in city } i \text { and city } j \text { ) }\end{array}$ & $\begin{array}{l}\text { Thomson-Reuters SCI } \\
\text { database }\end{array}$ \\
\hline PUBMASS2 & $\begin{array}{l}\text { Log of (product of total number of SCI } \\
\text { publications at provincial level); the city- } \\
\text { specific number is imputed from the city's } \\
\text { share of provincial GDP }\end{array}$ & $\begin{array}{l}\text { China Statistical Yearbook on } \\
\text { Science and Technology }\end{array}$ \\
\hline GDPMASS & $\begin{array}{l}\text { Log of (product of gross regional product in } \\
\text { city } i \text { and city } j \text { ) }\end{array}$ & $\begin{array}{l}\text { China City Statistical } \\
\text { Yearbook }\end{array}$ \\
\hline TEACHMASS & $\begin{array}{l}\text { Log of (product of higher education teachers } \\
\text { in city } i \text { and city } j \text { ) }\end{array}$ & $\begin{array}{l}\text { China City Statistical } \\
\text { Yearbook }\end{array}$ \\
\hline UNIMASS & $\begin{array}{l}\text { Log of [(product of number of national } \\
\text { universities funded by Project } 211 \text { in city } i \\
\text { and city } j)+1]\end{array}$ & $\begin{array}{l}\text { Ministry of Education and } \\
\text { other sources }\end{array}$ \\
\hline \multicolumn{3}{|l|}{ Spatial friction } \\
\hline DISTANCE & $\begin{array}{l}\text { Log of (geographic distance in kilometers } \\
\text { between city } i \text { and city } j \text { ) }\end{array}$ & Various sources \\
\hline \multicolumn{3}{|l|}{ Other variables } \\
\hline BEIJING & \multicolumn{2}{|l|}{$\begin{array}{l}1=\text { link connects Beijing; } 0=\text { link does not } \\
\text { connect Beijing }\end{array}$} \\
\hline SAME-PROVINCE & \multicolumn{2}{|l|}{$\begin{array}{l}1=\text { city } i \text { and } j \text { in same province; } 0=\text { city } i \\
\text { and } j \text { in different provinces }\end{array}$} \\
\hline \multicolumn{3}{|c|}{$\begin{array}{l}\text { Note: SCI-Science Citation Index. Except for PUBMASS, where we conform to comparable studies } \\
\text { by using the current year, all explanatory variables refer to observations two years before the beginning } \\
\text { of the studied time period: that is, } 1994,2000 \text {, and } 2006 \text {, if observations are available for these years. } \\
\text { In some cases we use the closest available year. }\end{array}$} \\
\hline
\end{tabular}

\section{Results}

\subsection{Descriptive analysis}

We present the number of coauthorships of each city with the other thirty cities in figure 1. Beijing, Shanghai, and Nanjing are top collaboration centers vis-à-vis other cities in all three periods. Guangzhou, Wuhan, and Hangzhou are also important, with Guangzhou and Hangzhou replacing Hefei and Shenyang from 2002 onward. The least important centers of coauthorships are roughly the same across all periods and include Guiyang, Nanchang, Nanning, Ningbo, Shijiazhuang, and Xiamen. Shenzhen is exceptional in that it became a much more interactive node between the second and third periods.

One way of looking at China's network structure is to identify the most intensive coauthorship links. Figures 2 and 3 show all links involving $0.25 \%$ or more of the total paper output of the thirty-one cities in 1996-98 and 2008-10, respectively. In the earlier period this implies at least 150 coauthored papers, while in the later period the cutoff point is 1000 papers. The increase reflects the rapid growth in China's science output.

What emerges is a Chinese science network that is Beijing centric. In the earlier period there were a total of twelve high-frequency links, eleven of which involve Beijing. In the later period the total number of links had increased to twenty-one links, with eighteen Beijing links. Since the identification of links is in relation to the total production of scientific papers 


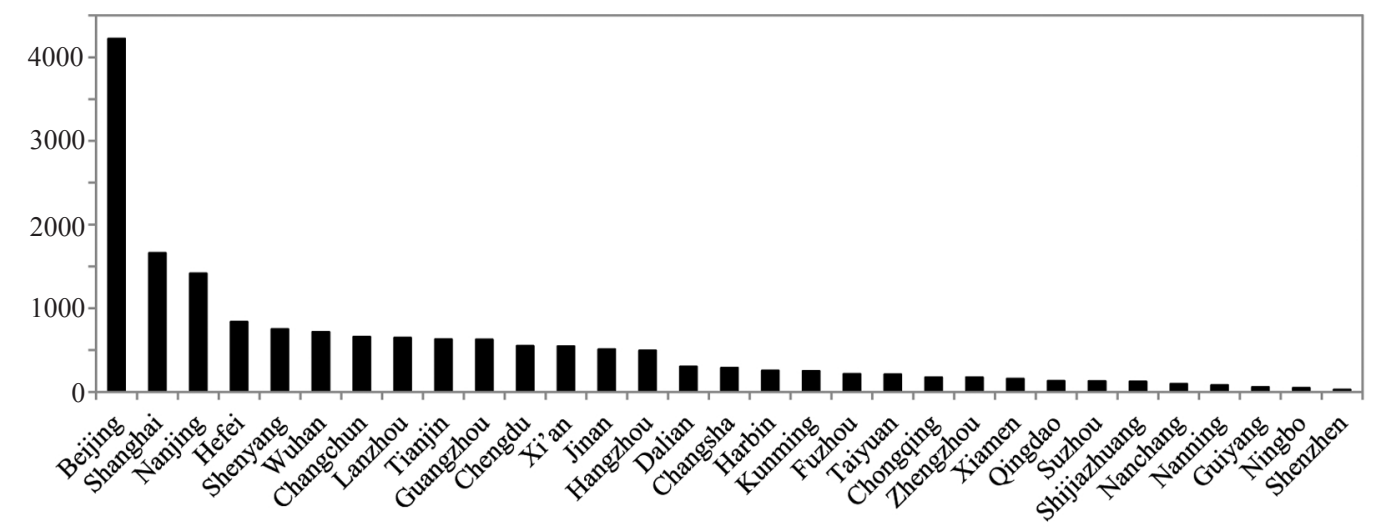

(a)

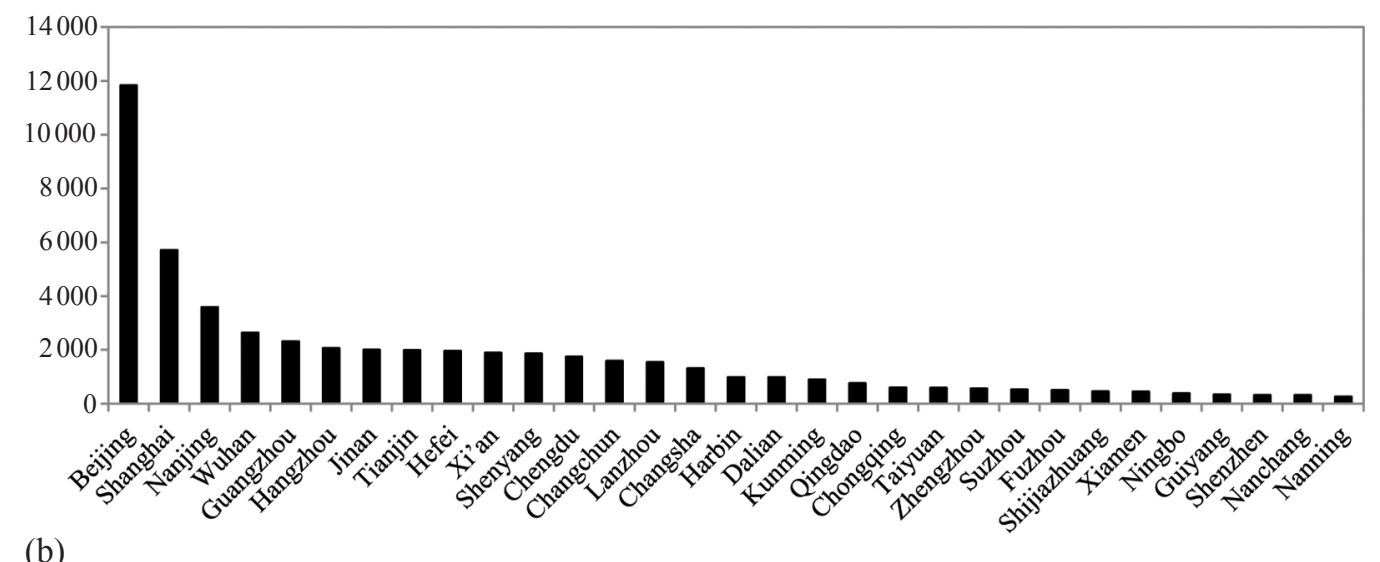

(b)

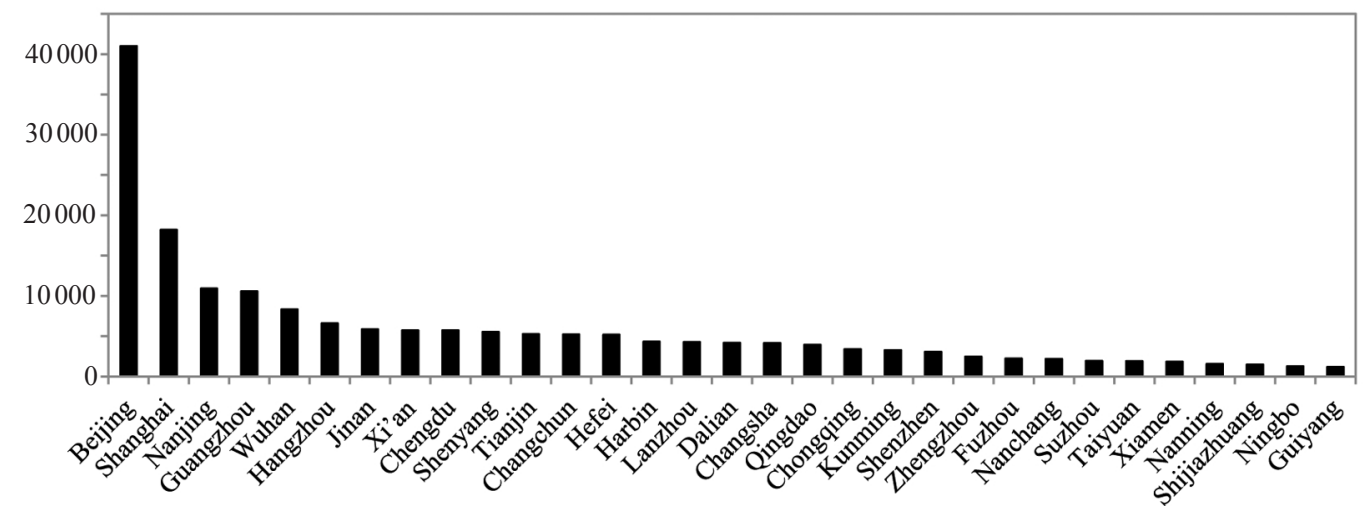

(c)

Figure 1. Total number of coauthored papers with other cities in three periods: (a) 1996-98, (b) 2002-04, (c) 2008-10.

in the relevant time period, the results show that intercity coauthorships increased in relative as well as absolute importance. China's science network became more interactive.

Figures 2 and 3 also hint at different hierarchical levels in the Chinese science network. The relevant criterion is whether a city has one or more high-frequency links to other cities. In the earlier period Beijing had such links with eleven cities. These eleven cities were all among the top seventeen in total science output, and all are provincial capitals. In the second 


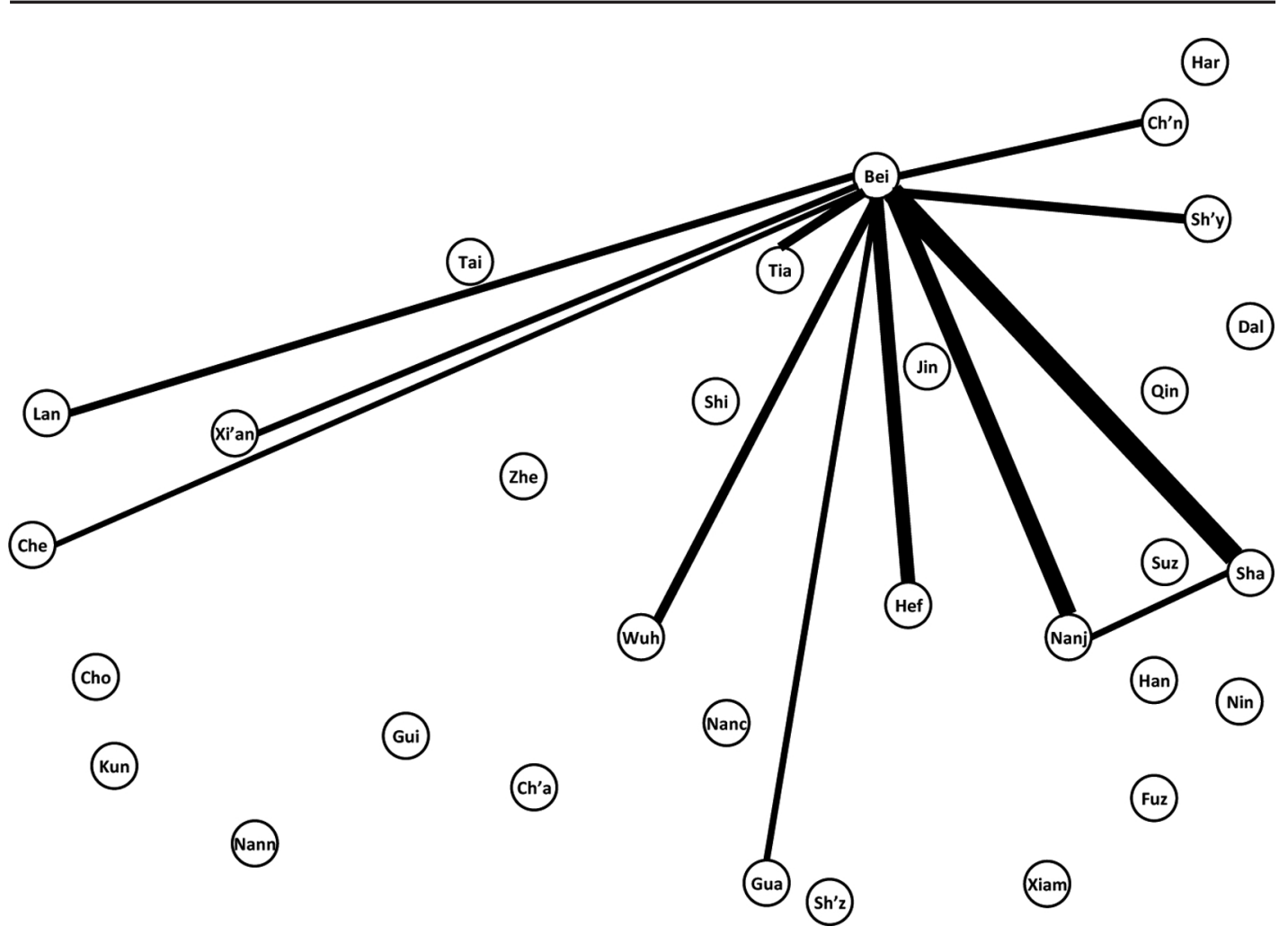

Figure 2. Intercity coauthorship links of 150 papers or more, 1996-98.

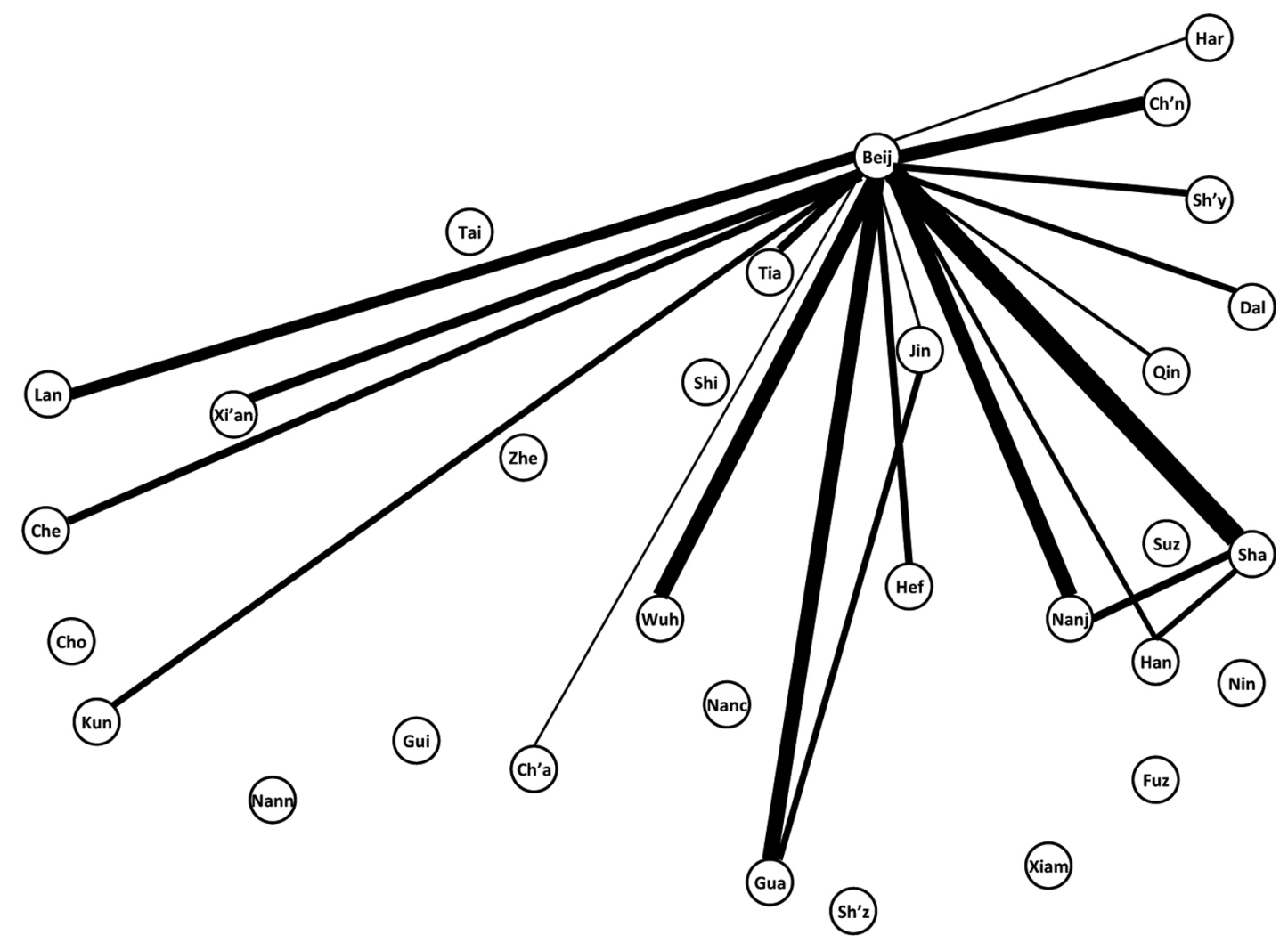

Figure 3. Intercity coauthorship links of 1000 papers or more, 2008-10. 
period the second level encompassed eighteen of the nineteen largest Chinese science cities after Beijing in SCI output terms. The second period also exhibited what may prove to be two emergent tendencies: two non-Beijing links in the Yangtze River Delta region as well as two links between Beijing and cities that are not provincial capitals (Dalian and Qingdao).

\subsection{Gravity results}

Table 4 gives the results of estimated pooled negative binomial regressions with five different specifications. The five regressions cover all three time periods and include the logarithm of the product of the SCI publication volumes in cities $i$ and $j$ as well as the logarithm of the distance in kilometers between $i$ and $j$.

Model 1 is the basic model with only mass and distance, while models $2-5$ introduce various refinements. Models 2 and 3 introduce city fixed effects, while model 4 employs Beijing and same-province dummies instead of thirty fixed effects. Models 3 and 4 use time dummies to account for time trends. Model 5 uses combined city-and-time fixed effects.

As expected, an increase in the product of the total number of publications is associated with an increase in the number of coauthored papers. The coefficient estimates range from 0.63 to 0.84 , which is in line with comparable prior studies (Ponds et al, 2007; Scherngell and $\mathrm{Hu}, 2011)$. The distance effects have the expected negative sign and are highly significant. The estimated magnitudes are all in the vicinity of -0.30 . Most comparable studies report distance effects between -0.23 and -0.70 , implying that spatial friction is not a greater impediment to interaction in China than in the West (see Hoekman et al, 2009; Scherngell and $\mathrm{Hu}, 2011$ ). We may interpret this result as indirect evidence that China's transport and communication infrastructures are unusually advanced for a middle-income country.

Table 4. Pooled negative binomial results. Dependent variable: coauthored papers.

\begin{tabular}{|c|c|c|c|c|c|}
\hline & $\begin{array}{l}1 \\
\text { no fixed } \\
\text { effects }\end{array}$ & $\begin{array}{l}2 \\
\text { fixed effects }\end{array}$ & $\begin{array}{l}3 \\
\text { fixed effects } \\
\text { and time } \\
\text { dummies }\end{array}$ & $\begin{array}{l}4 \\
\text { Beijing, same- } \\
\text { province and } \\
\text { time dummies }\end{array}$ & $\begin{array}{l}5 \\
\text { city and } \\
\text { time fixed } \\
\text { effects }\end{array}$ \\
\hline PUBMASS & $\begin{array}{l}0.717^{* * *} \\
(0.011)\end{array}$ & $\begin{array}{l}0.632 * * * \\
(0.011)\end{array}$ & $\begin{array}{l}0.760^{* * *} \\
(0.020)\end{array}$ & $\begin{array}{l}0.837^{* * *} \\
(0.019)\end{array}$ & $\begin{array}{l}0.757 * * * \\
(0.023)\end{array}$ \\
\hline DISTANCE & $\begin{array}{l}-0.319 * * * \\
(0.032)\end{array}$ & $\begin{array}{l}-0.335^{* * *} \\
(0.031)\end{array}$ & $\begin{array}{l}-0.310^{* * *} \\
(0.034)\end{array}$ & $\begin{array}{l}-0.226^{* * * *} \\
(0.033)\end{array}$ & $\begin{array}{l}-0.309 * * * \\
(0.034)\end{array}$ \\
\hline BEIJING & & & & $\begin{array}{l}0.527 * * * \\
(0.061)\end{array}$ & \\
\hline SAME-PROVINCE & & & & $\begin{array}{l}1.102 * * * \\
(0.131)\end{array}$ & \\
\hline City fixed effects & no & yes & yes & no & no \\
\hline Beijing effect & no & no & no & yes & no \\
\hline Same-province effect & no & no & no & yes & no \\
\hline Time dummies & no & no & yes & yes & no \\
\hline City-time fixed effects & no & no & no & no & yes \\
\hline Dispersion parameter $(\alpha)$ & $\begin{array}{l}0.583 * * * \\
(0.029)\end{array}$ & $\begin{array}{l}0.373 * * * \\
(0.028)\end{array}$ & $\begin{array}{l}0.355 * * * \\
(0.029)\end{array}$ & $\begin{array}{l}0.414 * * * \\
(0.031)\end{array}$ & $\begin{array}{l}0.334 * * * \\
(0.026)\end{array}$ \\
\hline Number of observations & 1395 & 1395 & 1395 & 1395 & 1395 \\
\hline Log likelihood & -5706.73 & -5476.58 & -5445.29 & -5527.06 & -5410.47 \\
\hline Pseudo $R^{2}$ & 0.177 & 0.210 & 0.215 & 0.203 & 0.220 \\
\hline \multicolumn{6}{|l|}{$* * *: p<0.01$} \\
\hline
\end{tabular}


Model 4 shows that there are more interactions with Beijing than the output volume of the city and its geographic location vis-à-vis other Chinese cities jointly imply. This result corroborates Beijing's role as a top-level coordination center in the network. That a Beijing link should be attractive to scientists in other localities is unsurprising; the Chinese Academy of Sciences is in Beijing as are China's two global top-fifty universities (Peking University and Tsinghua University). ${ }^{(14)}$ Consequently, Beijing-based scientists receive a disproportionate share of science funding (Feng and Pei, 2011). This is the first result in support of the first hypothesis regarding spatial political bias, which is that Beijing is overrepresented in coauthorships even after having accounted for its overrepresentation in China's science output, given the size of Beijing's economy relative to other Chinese cities.

There is also a significant same-province effect, implying more intraprovincial collaboration than volume and spatial proximity considerations would lead us to expect. This supports the hypothesis of a same-province bias, even after controlling for the spatial proximity of same-province cities.

Likelihood ratio tests indicate that models 1, 2, and 4 are nested in models 3 and 5, whereas model 3 is not nested in model 5 . In other words, models with city fixed effects and time dummies - entered either separately or jointly — outperform simpler regressions. These models are similar to Hoekman et al's (2010) models of interregional scientific interaction in Europe. Their estimated distance coefficient for aggregate science equaled -0.57 for 2000-07, after controlling for regional, national, and linguistic border effects. There is thus some evidence that spatial friction may have a greater inhibitory effect in Europe than in China. This might suggest that national boundaries affect cross-border scientific cooperation in ways that are not easy to control for in formal models (Okubo and Zitt, 2004).

Table 5 decomposes the analysis into the three time periods, using cross-sectional models. The estimated variable coefficients show a great deal of consistency from one period to the next, with significant mass and distance effects. The distance effect first increases and then decreases over this time period. One possible explanation is that there are two opposing effects at work: one where scientists in peripheral cities increasingly enter into long-distance research relationships; and one that reflects decreasing spatial friction as a result of investments in interregional transport infrastructure. A decomposition of these potential opposing tendencies is, however, unfeasible with the available data.

The functions with Beijing and same-province dummies show that the Beijing effect increases over time. Though other cities are increasing their contributions to China's total science output, there is also an increasing tendency-in relative terms-for coauthored papers to involve Beijing-based scientists. There are thus indications that the top-level monocentricity of the spatial political bias increased between 1996 and 2010. The increasing 'network monocentricity' is not necessarily intentional; it might be an unintended consequence of the tendency of scientists from smaller cities to seek out collaboration partners in the core so as to gain greater resource access (Acosta et al, 2011).

The same-province dummy estimates imply that the provincial aspect of the spatial political bias is also increasing. China thus offers a stark contrast to the evolution of the European science network as estimated by Hoekman et al (2010). While national borders are becoming less important impediments to European scientific cooperation, our results imply that provincial borders are becoming more important in China. Hence, there are indications that regional protectionism not only exists at the provincial level, but also that it may be increasing over time. Such protectionism may constitute the main impediment to

${ }^{(14)}$ Such links may partly be explained by the fact that some institutes of the Chinese Academy of Sciences often fund research and have links with institutes in other cities. 
Table 5. Cross-sectional negative binomial results. Dependent variable: coauthored papers.

\begin{tabular}{|c|c|c|c|c|c|c|}
\hline & $\begin{array}{l}1 \\
\text { 1996-98: } \\
\text { fixed effects }\end{array}$ & $\begin{array}{l}2 \\
\text { 1996-98: } \\
\text { Beijing } \\
\text { and same- } \\
\text { province } \\
\text { dummies }\end{array}$ & $\begin{array}{l}3 \\
2002-04: \\
\text { fixed effects }\end{array}$ & $\begin{array}{l}4 \\
2002-04: \\
\text { Beijing } \\
\text { and same- } \\
\text { province } \\
\text { dummies }\end{array}$ & $\begin{array}{l}5 \\
2008-10: \\
\text { fixed effects }\end{array}$ & $\begin{array}{l}6 \\
2008-10 \text { : } \\
\text { Beijing } \\
\text { and same- } \\
\text { province } \\
\text { dummies }\end{array}$ \\
\hline PUBMASS & $\begin{array}{l}0.811^{* * *} \\
(0.040)\end{array}$ & $\begin{array}{l}0.853^{* * *} \\
(0.035)\end{array}$ & $\begin{array}{l}0.768^{* * * *} \\
(0.041)\end{array}$ & $\begin{array}{l}0.844 * * * \\
(0.037)\end{array}$ & $\begin{array}{l}0.695^{* * *} \\
(0.040)\end{array}$ & $\begin{array}{l}0.816^{* * *} \\
(0.029)\end{array}$ \\
\hline DISTANCE & $\begin{array}{l}-0.271 * * * \\
(0.066)\end{array}$ & $\begin{array}{l}-0.200^{* * *} \\
(0.067)\end{array}$ & $\begin{array}{l}-0.339 * * * \\
(0.068)\end{array}$ & $\begin{array}{l}-0.284 * * * \\
(0.061)\end{array}$ & $\begin{array}{l}-0.312 * * * \\
(0.052)\end{array}$ & $\begin{array}{l}-0.200^{* * *} \\
(0.051)\end{array}$ \\
\hline BEIJING & & $\begin{array}{l}0.420^{* * *} \\
(0.110)\end{array}$ & & $\begin{array}{l}0.474 * * * \\
(0.113)\end{array}$ & & $\begin{array}{l}0.678 * * * \\
(0.104)\end{array}$ \\
\hline SAME-PROVINCE & & $\begin{array}{l}0.882 * * * \\
(0.271)\end{array}$ & & $\begin{array}{l}1.094^{* * *} \\
(0.285)\end{array}$ & & $\begin{array}{l}1.282 * * * \\
(0.144)\end{array}$ \\
\hline City fixed effects & yes & no & yes & no & yes & no \\
\hline Beijing effect & no & yes & no & yes & no & yes \\
\hline $\begin{array}{l}\text { Same-province } \\
\text { effect }\end{array}$ & no & yes & no & yes & no & yes \\
\hline $\begin{array}{l}\text { Dispersion } \\
\text { parameter }(\alpha)\end{array}$ & $\begin{array}{l}0.422 * * * \\
(0.056)\end{array}$ & $\begin{array}{l}0.537 * * * \\
(0.067)\end{array}$ & $\begin{array}{l}0.414 * * * \\
(0.048)\end{array}$ & $\begin{array}{l}0.508 * * * \\
(0.054)\end{array}$ & $\begin{array}{l}0.251 * * * \\
(0.036)\end{array}$ & $\begin{array}{l}0.305 * * * \\
(0.039)\end{array}$ \\
\hline $\begin{array}{l}\text { Number of } \\
\text { observations }\end{array}$ & 465 & 465 & 465 & 465 & 465 & 465 \\
\hline Log-likelihood & -1250.37 & -1281.19 & -1788.86 & -1828.07 & -2354.50 & -2398.87 \\
\hline Pseudo $R^{2}$ & 0.225 & 0.206 & 0.188 & 0.170 & 0.179 & 0.163 \\
\hline
\end{tabular}

future integration (Yoon, 2011), since falling space-bridging costs imply that spatial friction is becoming less of an obstacle to interprovincial scientific interaction.

The final set of regressions consists of negative binomial panels with random effects. The panels introduce four new specifications with exogenous mass variables along with the original one. All four regressions serve as robustness checks, with the last two being closer to Beckmann's input model (TEACHMASS and UNIMASS) and a GDPMASS versus UNIMASS comparison relating to the markets-versus-politics dichotomy.

Table 6 presents the results. The results suggest that there are many ways of approximating mass, and that the distance effect is relatively robust across specifications. The more exogenous measures of mass are all robust predictors of scientific interaction, while a critical look at the popular but potentially more endogenous measure PUBMASS suggests that it may overestimate the size effect. A comparison between GDPMASS and UNIMASS reveals that UNIMASS is the more significant predictor of scientific collaboration. This again hints at the importance of political resource allocation in science as opposed to market-driven agglomeration effects. Outside China such agglomeration effects often dominate political allocation, as is attested by the dominant role of New York in financial research and the San Francisco Bay Area in information-technology-related science and engineering. San Francisco, not Washington, is America's largest and most connected science city. 
Table 6. Results of negative binomial panels with random effects. Dependent variable: coauthored papers.

\begin{tabular}{|c|c|c|c|c|c|}
\hline & $\begin{array}{l}1 \\
\text { PUBMASS }\end{array}$ & $\begin{array}{l}2 \\
\text { PUBMASS2 }\end{array}$ & $\begin{array}{l}3 \\
\text { GDPMASS }\end{array}$ & $\begin{array}{l}4 \\
\text { TEACHMASS }\end{array}$ & $\begin{array}{l}5 \\
\text { UNIMASS }\end{array}$ \\
\hline PUBMASS & $\begin{array}{l}0.822 * * * \\
(0.022)\end{array}$ & & & & \\
\hline PUBMASS2 & & $\begin{array}{l}0.393 * * * \\
(0.023)\end{array}$ & & & \\
\hline GDPMASS & & & $\begin{array}{l}0.539^{* * *} \\
(0.050)\end{array}$ & & \\
\hline TEACHMASS & & & & $\begin{array}{l}0.554 * * * \\
(0.020)\end{array}$ & \\
\hline UNIMASS & & & & & $\begin{array}{l}0.713 * * * \\
(0.045)\end{array}$ \\
\hline DISTANCE & $\begin{array}{l}-0.286^{* * * *} \\
(0.045)\end{array}$ & $\begin{array}{l}-0.238^{* * *} \\
(0.061)\end{array}$ & $\begin{array}{l}-0.237 * * * \\
(0.066)\end{array}$ & $\begin{array}{l}-0.428^{* * *} \\
(0.060)\end{array}$ & $\begin{array}{l}-0.376^{* * *} \\
(0.067)\end{array}$ \\
\hline Time dummies & yes & yes & yes & yes & yes \\
\hline $\begin{array}{l}\text { Dispersion } \\
\text { parameter }(\alpha)\end{array}$ & $\begin{array}{l}0.355^{* * * *} \\
(0.024)\end{array}$ & $\begin{array}{l}0.934 * * * \\
(0.058)\end{array}$ & $\begin{array}{l}1.286^{* * *} \\
(0.761)\end{array}$ & $\begin{array}{l}0.355^{* * *} \\
(0.029)\end{array}$ & $\begin{array}{l}0.502 * * * \\
(0.030)\end{array}$ \\
\hline $\begin{array}{l}\text { Number of } \\
\text { observations }\end{array}$ & 1395 & 1395 & 1395 & 1395 & 1395 \\
\hline Log-likelihood & -5303.78 & -5733.38 & -5834.81 & -5762.63 & -5760.59 \\
\hline Pseudo $R^{2}$ & 0.213 & 0.149 & 0.134 & 0.145 & 0.145 \\
\hline
\end{tabular}

\section{Understanding the gravity results: an exploratory analysis}

A simple descriptive network analysis is helpful for identifying which particular intercity linkages are most important for the Beijing and same-province effects. One way of revealing strong links is to identify whether links are stronger or weaker than expected in a relative sense, controlling for mass, but not for distance. Thus we should expect all stronger-thanexpected links to consist exclusively of the most geographically proximate cities, in the absence of spatial political biases.

If there were no spatial friction, the expected number of coauthorships involving city $i$ and city $j$ should equal the product of the number of coauthored articles (with all cities in the network) in the two cities divided by the total number of network coauthorships. Figure 4 shows those links where the observed number of coauthorships exceeds 150 percent of the expected number. Lines of medium thickness imply between two and three times as many observed as expected coauthorships, while the thickest lines imply observed frequencies that are over three times greater than expected. Table 7 shows the ten links with the highest ratios between observed and expected coauthorships. It is the identification of disproportionately strong links that makes it possible to construct proximity clusters such as Taylorite 'bands'.

Figure 4 reveals two tendencies. First, Beijing's strongest links are with cities with small SCI publication volumes, including geographically remote ones such as Kunming and Guiyang. Its six disproportionately strong links are with cities that are ranked 10th, 17th, 20th, 25th, 28th, and 31st in output (see table 2). Another aspect of this tendency is that the smallest science cities tend to have numerous strong links. Guiyang, Kunming, Nanchang, Nanning, Ningbo, Shijiazhuang, Suzhou, and Taiyuan have three or four strong links each. 


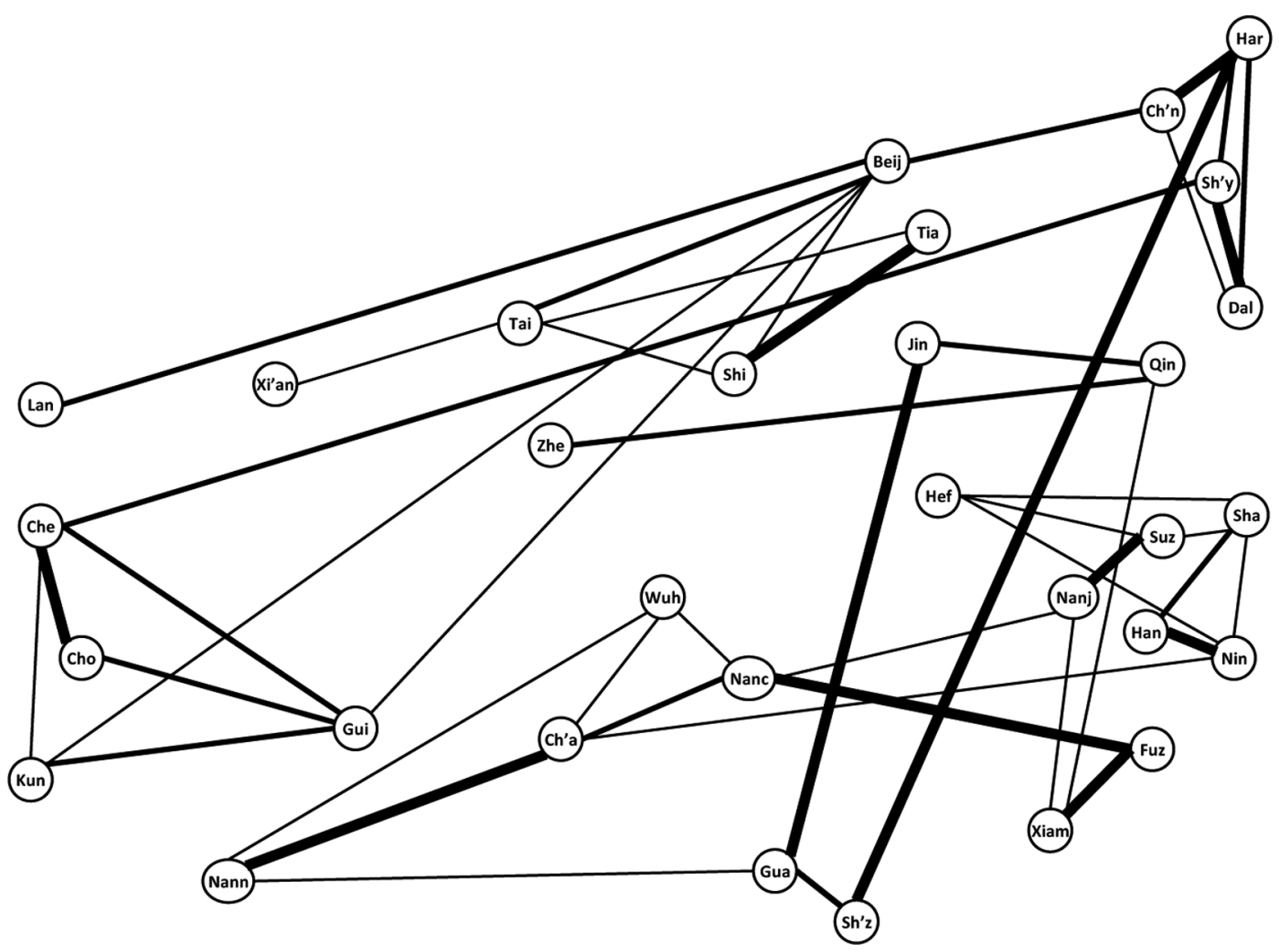

Figure 4. Strong intercity coauthorship links in China, 2008-10.

Table 7. Top-ten overrepresented links, 2008-10.

\begin{tabular}{lll}
\hline City $i$ & City $j$ & Overrepresentation $(\%)$ \\
\hline Xiamen & Fuzhou & 791.3 \\
Hangzhou & Ningbo & 728.5 \\
Chengdu & Chongqing & 512.7 \\
Harbin & Shenzhen & 507.9 \\
Guangzhou & Jinan & 417.0 \\
Changsha & Nanning & 386.5 \\
Tianjin & Shijiazhuang & 385.9 \\
Changchun & Harbin & 385.7 \\
Shenyang & Dalian & 346.1 \\
Nanjing & Suzhou & 334.6 \\
\hline
\end{tabular}

It is likely that this reflects intercity cooperation strategies among universities in cities with small local knowledge stocks. This strategy should be especially attractive in China, since scientists working at top-ranked national universities have better access to national research funds. The second tendency is proximity clustering in regional bands, with the strongest links being intraprovincial. There are six intraprovincial pairings of cities, four of which are among the ten links with the greatest observed-to-expected ratios (see table 7). The remaining two intraprovincial links are also stronger than expected.

Each of the eight city pairs in bold font in table 7 represents a link between cities in the same part of China, which implies proximity clustering. Although short geographic distances may be a partial explanation, both figure 4 and table 7 hint at an independent provincial effect. In the Yangtze River Delta region, Suzhou in Jiangsu is more strongly 
linked to Nanjing (Jiangsu) than to Shanghai, though the latter city is nearer. Hangzhou in Zhejiang links to Ningbo (Zhejiang) but not to equidistant Suzhou. And Nanjing does not have a strong link to Hefei. This could be an indication that second-ranked provincial cities seek linkages to the provincial capital, which hosts national universities as well as provincial funding organizations. A conjecture is therefore that China's science network consists of at least three levels. There is also the possibility that each province makes up a band of closely connected cities, with hierarchical control functions vested in the provincial capital. A likely consequence of this province-level home bias is that it impedes effective knowledge transfer across China (Chen and Wang, 2003; Hui, 2007; Yoon, 2011).

The Guangzhou-Jinan and Shenzhen-Harbin links may seem puzzling. These links reflect a new expansion strategy among some cities with modest science agglomerations. Several such cities have pursued scientific cooperation with other cities so as to attain rapid scientific growth. Important means include national initiatives such as the 973 and 211 Programs. The 973 Program funds large-scale research projects, including topic-specific projects involving universities in several Chinese cities. The 211 Program is even more important, since it receives most Chinese research funding and includes most national key laboratories. These laboratories sometimes encompass universities in different provinces $(\mathrm{Hu}$ and Jefferson, 2008; Jonkers, 2010, page 25). ${ }^{(15)}$ The UNIMASS variable in table 6 is a measure of the impact of the 211 Program, since it measures the number of national universities funded by it.

Shenzhen's expansion involves more than these programs, however. In 2002, the city government decided to build a university zone and encouraged national universities from elsewhere to set up graduate schools in Shenzhen. The Harbin Institute of Technology is the most prominent such school. This could explain how Shenzhen has not only progressed rapidly in scientific collaboration after the 2002-04 period but also why the ShenzhenHarbin link is so strong. Though unusual, the strong Guangzhou-Jinan and Shenzhen-Harbin linkages both owe their strength to political rather than market interactions.

Overall, the network patterns suggest a strong connection between the spatial structure of Chinese science and political resource allocation. Beijing dominates nationally, and provincial capitals dominate provinces. All top universities are public, and research funds are governmental. Rich cities with a strong market orientation but less political power-such as Ningbo, Shenzhen, and Suzhou - have modest publication volumes, albeit with high growth rates. The smaller science cities are growing, but the deck is still stacked in Beijing's favor.

Figure 5 shows an exploratory Chinese system of science cities. ${ }^{(16)}$ It depicts China's publication and coauthorship structure along the lines of earlier studies of world science cities; cities thus belong to hierarchical levels and possibly also to bands of strong links. The uppermost level consists of Beijing alone, with the second-tier cities being Shanghai,

${ }^{(15)}$ We thank a referee for pointing this out to us. Our own search of the Ministry of Education and Ministry of Science and Technology sources revealed that Sun Yat-Sen University (Guangzhou based) and Shandong University (Jinan based) have well-established links and jointly participate in a major research project that also includes Nankai University, Peking University, and Hangzhou Normal University.

${ }^{(16)}$ Beijing has much greater volume and network connectivity than other cities and is the only toplevel city. We used quantitative thresholds to allocate cities to levels $2-4$. The measured quantities refer to the most recent period (2008-10). During that period, level-2 cities generated at least 15000 SCI papers, of which at least 6500 were coauthored together with authors from the other thirty Chinese cities. Level-3 cities have at least 8000 SCI papers and 4000 intercity coauthorships. There is also a third criterion, which reflects the diversification of a city's intercity connectivity. The third criterion conforms to the 'world network of science cities' literature, where cities closer to the innermost concentric circle have more 'global' connectivity. The criteria explain why both Xi'an and Jinan are at level 3 rather than level 2: Xi' an produces more than 15000 papers but is less connected and spatially diversified than Jinan, while Jinan's overall publication output is too small (see table 2 and figure 1). 


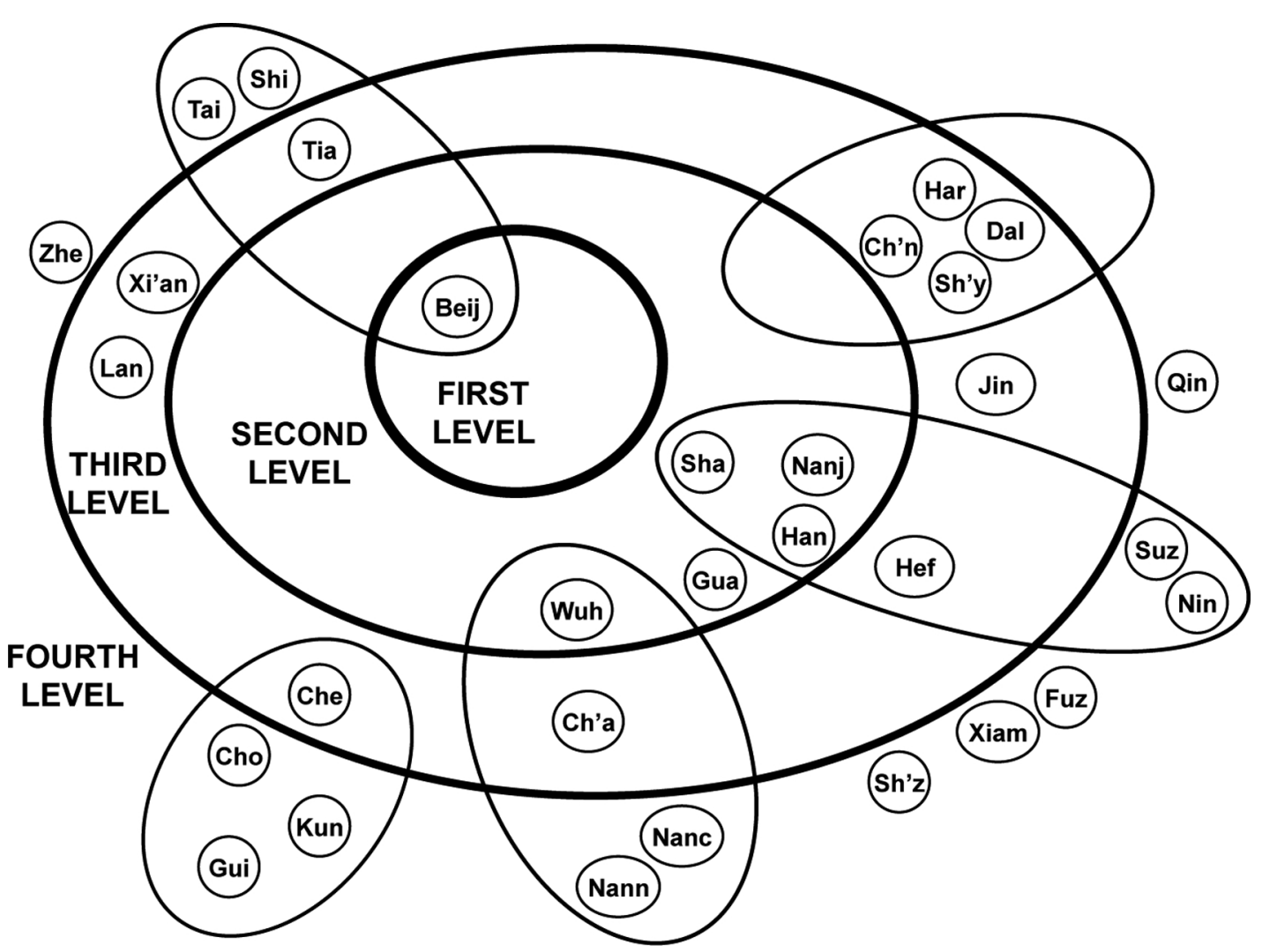

Figure 5. Levels and bands in the Chinese system of science cities.

Nanjing, Wuhan, Guangzhou, and Hangzhou. A higher hierarchical level implies greater overall network connectivity. On the whole, the picture that emerges is a monocentric network.

There are several instances of regional bands involving cities at different levels. The indicated bands are the North (led by Beijing), the Yangtze River Delta (Shanghai), the Northeast (nonhierarchical), the Center (Wuhan); and the West (Chengdu).

\section{Conclusion}

Chinese science is on the rise. This paper explores the geography of Chinese science, with a focus on the role of China's spatial political bias, which manifests itself as Beijing and same-province effects. Gravity-type models reveal that mass and distance variables conform to the global pattern, but with slightly less spatial friction and with an orientation towards coauthorships involving Beijing-based scientists. The relatively low level of spatial friction alludes to large center-periphery distances and well-functioning transport and communication infrastructures for intercity flows of people and ideas.

The presence of a same-province effect implies lower level spatial political bias. Moreover, both the Beijing and the home-province biases became more pronounced between 1996 and 2010, which is the opposite of what happened in Europe.

Our exploratory network analysis found a spatial organization of Chinese science where Beijing alone occupies the highest hierarchical level. Though there is scientific growth elsewhere in the system, Beijing continues to dominate. This analysis also hints at the existence of 'regional bands' of cities. Unusually strong intraprovincial links reflect the regional dimension of China's spatial political bias. 
Overall, our results show that political decisions rather than markets shape the spatial resource allocation of scientific resources. In a market-led spatial organization of science, one would expect a city's scientific output and connectivity to reflect general knowledge-related agglomeration economies. Not so in China, where Beijing is twice as large as Shanghai and thirty times larger than Shenzhen, and with even greater differentials in terms of network connectivity. We think that this bias reflects the absence of a true market for ideas in China. Coase and Wang (2013) contend that China's central planning of ideas (including science) is its greatest economic problem. They write that

"Chinese universities have become more skilled in currying favor with the Ministry of Education than in offering innovative research and educational progress; this situation is not so different from state-owned enterprises before reform. ... As far as Chinese universities are concerned, the government essentially controls both inputs (finance and personnel) and outputs (degree programs), leaving them very little autonomy" (pages 191-192).

While China has arrived on the world stage of science, it still occupies a peripheral position in the production of new scientific breakthroughs. Even Beijing lacks the impact of Western cities with similar publication volumes, such as London or Paris (Nature, 2013; Royal Society, 2011). The main challenge will be to break out of this isolation. The problem is all the more daunting since it may be more cultural than political. It is a problem that mainland China shares with Japan, South Korea, and Taiwan (Andersson et al, 2013). When scientists around the world look for path-breaking ideas they still prefer Cambridge-whether in England or Massachusetts - over Beijing or Tokyo. To break out of this impasse, China may need a new 'cultural revolution' more than it needs money.

\section{References}

Acosta M, Coronado D, Ferrándiz E, León M D, 2011, "Factors affecting inter-regional academic scientific collaboration within Europe: the role of economic distance" Scientometrics 87 63-74

Andersson $\AA$ E, Andersson D E, 2006 The Economics of Experiences, the Arts and Entertainment (Edward Elgar, Cheltenham, Glos)

Andersson Å E, Persson O, 1993, "Networking scientists" Annals of Regional Science 27 11-21

Andersson Å E, Andersson D E, Matthiessen C W, 2013 Öresundsregionen: den dynamiska metropolen (Dialogos, Stockholm)

Beckmann M, 1993, "Knowledge networks: the case of scientific interaction at a distance" Annals of Regional Science 27 5-9

Beckmann M, 1994, "On knowledge networks in science: collaboration among equals" Annals of Regional Science 28 233-242

Beckmann M, 1999 Lectures on Location Theory (Springer, Berlin)

Chen C T, Wang T, 2003, "The influence to the local S\&T legislation from the view of CAST operation mode forum on science and technology in China" Forum on Science and Technology in China 4 3-6 [in Chinese]

Coase R, Wang N, 2013 How China Became Capitalist (Palgrave Macmillan, Basingstoke, Hants)

Feng Z H, Pei T C, 2011, “The '10 billion' cake: National Natural Science Foundation of China” Journal of Thoracic Disease 3 213-216

Frenken K, Hardeman S, Hoekman J, 2009, "Spatial scientometrics: towards a cumulative research program" Journal of Informetrics $3222-232$

Hansen T, 2013, "Bridging regional innovation: cross-border collaboration in the Øresund Region" Geografisk Tidsskrift-Danish Journal of Geography 113(1) 25-38

Havemann F, Heinz M, Kretschmer H, 2006, "Collaboration and distances between German immunological institutes - a trend analysis" Journal of Biomedical Discovery and Collaboration $11-7$

Hennemann S, Wang T, Liefner I, 2011, "Measuring regional science networks in China: a comparison of international and domestic bibliographic data sources" Scientometrics 88 839-857 
Hilbe J M, 2011 Negative Binomial Regression 2nd edition (Cambridge University Press, Cambridge)

Hoekman J, Frenken K, van Oort F, 2009, "The geography of collaborative knowledge production in Europe" Annals of Regional Science 43 721-738

Hoekman J, Frenken K, Tijssen R J W, 2010, "Research collaboration at a distance: changing spatial patterns of scientific collaboration within Europe" Research Policy 39 662-673

Hu A G Z, 2010, "Propensity to patent, competition and China's foreign patenting surge" Research Policy 39 985-993

Hu A G Z, Jefferson, G H, 2008, "Science and technology in China", in China's Great Economic Transformation Eds L Brandt, TG Rawski (Cambridge University Press, Cambridge) pp 286-336

Hui L, 2007, "Sub-national innovation system practices in China", paper presented at the national workshop on sub-national innovation systems and technology capacity building policies to enhance competitiveness of SMEs, organized by UN-ESCAP and Indonesian Institute of Sciences (LIPI), 3-4 April, Jakarta, Indonesia

Isard W, 1960 Methods of Regional Analysis: An Introduction to Regional Science (MIT Press, Cambridge, MA)

Jonkers K, 2010 Mobility, Migration and the Chinese Scientific Research System (Routledge, London)

Katz J S, 1994, "Geographical proximity and scientific collaboration" Scientometrics 31 31-43

Liang L, Zhu L, 2002, "Major factors affecting China's inter-regional research collaboration: regional scientific productivity and geographical proximity" Scientometrics $\mathbf{5 5}$ 287-316

Liefner I, Hennemann S, 2011, "Structural holes and new dimensions of distance: the spatial configuration of the scientific knowledge network of China's optical technology sector" Environment and Planning A $\mathbf{4 3} 810-829$

Liu X, Derudder B, Liu Y, Witlox F, Shen W, 2013, “A stochastic actor-based modelling of the evolution of an intercity corporate network" Environment and Planning A 45(4) 947-966

Marginson S, 2011. "Higher education in East Asia and Singapore: rise of the Confucian Model" Higher Education 61 587-611

Matthiessen C W, Schwarz A W, Find S, 2002, "The top-level global research system, 1997-99: centres, networks and nodality. An analysis based on bibliometric indicators" Urban Studies 39 903-927

Matthiessen C W, Schwarz A W, Find S, 2010, "World cities of scientific knowledge: systems, networks and potential dynamics. An analysis based on bibliometric indicators" Urban Studies 47 1879-1897

Matthiessen C W, Schwarz A W, Find S, 2011, "Research nodes and networks", in Handbook of Creative Cities Eds D E Andersson, Å E Andersson, C Mellander (Edward Elgar, Cheltenham, Glos) pp 211-228

Nature, 2013 Nature Publishing Index 2012: China (Nature Publishing Group, London)

Okubo Y, Zitt M, 2004, "Search for research integration across Europe: a closer look at international and inter-regional collaboration in France" Science and Public Policy 31 213-226

Oner A C, Mitsova A, Prosperi D, Vos J, 2010, "Knowledge globalization in urban studies and planning: a network analysis of international co-authorships" Journal of Knowledge Globalisation $32-30$

Ponds R, van Oort F, Frenken K, 2007, "The geographical and institutional proximity of research collaboration" Papers in Regional Science 86 423-443

Royal Society, 2011 Knowledge, Networks and Nations: Global Scientific Collaboration in the 21st Century (Elsevier, Amsterdam)

Sassen S, 1991 The Global City: New York, London, Tokyo (Princeton University Press, Princeton, NJ)

Scherngell T, Hu Y, 2011, "Collaborative knowledge production in China: regional evidence from a gravity model approach" Regional Studies $\mathbf{4 5} 755-772$

Sen A, Smith T E, 1995 Gravity Models of Spatial Interaction Behavior (Springer, New York)

Taylor P J 2004 World City Network: A Global Analysis (Routledge, London)

White H D, 2011 "Scientific and scholarly networks", in The SAGE Handbook of Social Network Analysis Eds J P Scott, P Carrington (Sage, London) pp 271-285

Wilson A G, 1970 Entropy in Urban and Regional Modelling (Pion, London) 
Yoon J, 2011 Exploring Regional Innovation Capacities of PR China: Toward the Study of Knowledge Divide PhD thesis, School of History, Technology and Society, Georgia Institute of Technology Zhou P, Leydesdorff L, 2006, "The emergence of China as a leading nation in science" Research Policy 35(1) 83-104

Zhou P, Thijs B, Glänzel W 2009, "Regional analysis on Chinese scientific output" Scientometrics $81839-857$ 